\title{
O processo pedagógico da luta de gênero na luta pela terra: o desafio de transformar práticas e relações sociais ${ }^{1}$
}

\section{The pedagogical process of gender struggle within land struggle: the challenge of transforming social practices and relationships}

\author{
Sônia Fátima Schwendler²
}

\begin{abstract}
RESUMO
O presente artigo analisa o processo pedagógico da luta de gênero que ocorre dentro da luta pela terra a partir do protagonismo das mulheres trabalhadoras do campo. Com base na literatura da temática da educação, gênero e movimentos sociais e, a partir de extensa pesquisa de campo desenvolvida no Sul do Brasil com mulheres e homens do Movimento dos Trabalhadores Rurais Sem Terra (MST) e com o Movimento de Mulheres Camponesas (MMC), este estudo evidencia os principais elementos que contribuíram para o empoderamento das mulheres camponesas e a mutação das relações de gênero na luta pela terra. Ao examinar o impacto da intencionalidade socioeducativa na transformação das relações de gênero, argumenta-se que o saber social produzido na luta político-organizativa, a partir de uma leitura de classe e da influência da teoria feminista, promove a organização das mulheres camponesas em torno das demandas estratégicas de gênero com
\end{abstract}

DOI: $10.1590 / 0104-4060.39833$

1 As reflexões deste artigo integram a pesquisa de doutorado "A Emancipação da Mulher através da Participação na Luta pela Terra: Brasil e Chile", desenvolvida na Universidade de Londres, no Programa de Estudos Ibéricos e Latino-Americanos do Queen Mery College. (SCHWENDLER, 2013). Esta pesquisa contou com o financiamento da Universidade Central de Londres - grant awarded by the Academic Trust Funds committee from the Convocation Trust Appeal Fund for the Central Research Fund, e do Queen Mary College, além do apoio da Universidade Federal do Paraná e da Coordenação de Aperfeiçoamento de Pessoal de Nível Superior - CAPES, através da bolsa do Programa de Doutorado Pleno no Exterior.

2 Universidade Federal do Paraná. Curitiba, Paraná, Brasil. Rua General Carneiro, 460. CEP: $80.060-150$. 
vistas ao enfrentamento das desigualdades e da subalternização da mulher. Evidencia-se, no entanto, que apesar de sua importância, este processo pedagógico que emerge na dinâmica da luta social não é o suficiente para a transformação das relações de gênero. Há a necessidade de leis e políticas afirmativas que garantam à mulher condições efetivas de participação política, econômica e social.

Palavras-chave: Educação; gênero; mulheres; reforma agrária; movimentos sociais.

\begin{abstract}
This paper analyses the pedagogical process of gender struggle that takes place within the struggle for land from the agency of rural workers' women. Based on the literature on education, gender and social movements and, from extensive field work carried out in southern Brazil with women and men of the Landless Workers Movement (Movimento dos Trabalhadores Rurais Sem Terra-MST) and the Peasant Women's Movement (Movimento de Mulheres Camponesas - MMC), this study highlights the key elements that contributed to the empowerment of rural women and the shifting of gender relations within land struggle. When examining the impact of socio-educational intention in changing gender relations, it is argued that the social knowledge produced within the political-organizational struggle, from a class consciousness and the influence of feminist theory, promotes the organization of peasant women around strategic gender demands aiming to confront inequality and women's subordination. It is evident, however, that despite its importance, this pedagogical process which emerges in the dynamics of social struggle is not enough for the transformation of gender relations. There is a need for laws and affirmative action policies that guarantee effective conditions for women's political, economic and social participation.
\end{abstract}

Keywords: Education; gender; women; land reform; social movements.

\title{
Introdução
}

Nos movimentos sociais de campo, é notória a participação e a organização da mulher, que não apenas transgride sua invisibilidade social e política construída historicamente, mas também protagoniza a luta de gênero no espaço da luta pela terra. Em seu processo organizativo, o movimento social de luta pela terra dinamiza experiências sociopolítico-educativas que contribuem para 
a transformação das relações e identidades de gênero e para o desenvolvimento do capital social e político da mulher camponesa. Céli Pinto (1992) destaca três situações decorrentes da participação da mulher nos movimentos sociais de caráter popular: (1) a mulher deixa de atuar apenas nos limites do privado, provocando novas relações no interior da família e seu entorno; (2) a mulher passa a articular, no âmbito do movimento, lutas diferenciadas em relação aos homens; (3) aquelas mulheres, organizadas em torno de aspectos tradicionalmente femininos, passam a questionar a sua própria condição.

Partindo da análise da categoria de gênero como uma construção sócio-histórica. (SCOTT, 1986) enraizada no tempo e no lugar (BOYDSTON, 2008), compreende-se que a vivência de novas relações sociais e os papéis desempenhados pelas mulheres numa etapa da luta, “[...] ficam na memória enquanto significação e podem ser mantidas ou recobradas em situações concomitantes ou posteriores". (MELO, 2001, p. 175). Argumenta-se que a materialidade da luta social, a mutação das identidades e relações de gênero, o acesso da mulher camponesa ao conhecimento, sua emancipação política e sua organização têm promovido a luta feminista no interior da luta de classe. (SCHWENDLER, 2013). $\mathrm{Na}$ luta pela terra, elas (re)constroem seus saberes, sua cultura e participam da elaboração de uma cultura contra-hegemônica (GRAMSCI, 1984), no tocante aos "regimes patriarcais de gênero" (WALBY, 1997; JACOBS, 2010), que historicamente têm limitado a atuação das mulheres na sociedade.

Este artigo examina a dimensão pedagógica deste processo e o impacto da intencionalidade socioeducativa transformadora das relações de gênero. Esta educação que ocorre no interior dos movimentos sociais pode ser caracterizada como educação não formal, conforme Maria da Gloria Gohn (2006, p. 29), tendo em vista que há "[...] uma intencionalidade na ação, no ato de participar, de aprender e de transmitir ou trocar saberes." A Educação não formal designa, segundo Gohn (2006, p. 28), um processo com várias dimensões, entre elas: 1) a aprendizagem política dos direitos dos indivíduos enquanto cidadãos; 2 ) a capacitação dos indivíduos para o trabalho, por meio da aprendizagem de habilidades e/ou desenvolvimento de potencialidades; 3) a aprendizagem e o exercício de práticas que capacitam os indivíduos a se organizarem com objetivos comunitários; 4) a aprendizagem de conteúdos que possibilitem aos indivíduos fazerem uma leitura do mundo; 5) a educação desenvolvida na e pela mídia, em especial a eletrônica.

Diversos estudos têm demostrado que a luta social carrega uma pedagogia que educa quem dela participa. (GOHN, 1999; CALDART, 2000; ARROYO, 2003; SOUZA, 2006; SCHWENDLER, 2010). Ao estudar a luta pela terra, desenvolvida pelo Movimento dos Trabalhadores Rurais Sem Terra-MST, Roseli Caldart (2000) afirma que existe uma "pedagogia do movimento" que se constitui 
na historicidade das ações e das reflexões pedagógicas dos movimentos sociais. A autora demostra que a experiência da participação em uma organização coletiva como a do MST é formadora dos trabalhadores Sem Terra pelas "[...] relações sociais que produz e reproduz, e que acabam interferindo pedagogicamente em diversas dimensões do ser humano". (CALDART, 2000, p. 220)3.

Tendo por referência a luta pela terra do MST, este artigo ressalta, por um lado, o significado político e pedagógico da participação das mulheres nos espaços estratégicos da luta de classe, e por outro, o papel da teoria feminista e da auto-organização das mulheres na transformação das relações de gênero e na (re) construção da sua identidade política. Com base na pesquisa empírica, realizada em 2011, na região Sul do Brasil, através da história oral (PORTELLI, 2006; THOMPSON, 1988; MARRE, 1991) e, nos referenciais teóricos, argumenta-se que o saber social (DAMASCENO, 1993) produzido na práxis da luta social tem empoderado a mulher camponesa, promovendo sua politização e sua organização em torno de uma agenda de gênero. Verifica-se neste processo o papel da intencionalidade pedagógica que busca de forma estratégica construir um ambiente educativo que possibilite a problematização e a mutação das relações de gênero e, ao mesmo tempo, intervir nas políticas públicas e na organização do movimento social.

\section{A organização política e a inserção da mulher na luta social}

A dinâmica da luta social configura-se como um espaço educativo, de formação da consciência política e de gênero da mulher camponesa. Dois processos merecem destaque: a participação na luta pela terra e a organização no movimento autônomo de mulheres.

As mulheres Sem Terra participam da luta pela terra desde a primeira ocupação (1978) organizada pela Comissão Pastoral da Terra (CPT). A ocupação constitui-se em uma forma de resistência dos trabalhadores Sem Terra, diante da expropriação, do desemprego e das desigualdades resultantes do desenvolvimento contraditório do capitalismo. (FERNANDES, 2008). Em conjunto com as Comunidades Eclesiais de Base (CEBs) e o Novo Sindicalismo, a CPT contribuiu

3 Ser Sem Terra, expressão que usaremos neste artigo, é muito diferente do que ser um trabalhador rural que não possui terra, ou seja, um sem-terra, conforme definido no dicionário brasileiro. Segundo Caldart (2000, p. 25), Sem Terra é uma identidade produzida na luta coletiva, que embora se mantenha enraizada nas tradições camponesas, vincula os trabalhadores sem-terra a uma luta de classe. 
significativamente para a formação do Movimento dos Trabalhadores Rurais Sem Terra - MST, que se constitui em 1984 como um movimento nacional ${ }^{4}$.

No enfrentamento da questão agrária brasileira, dentre outros movimentos sociais congêneres, destaca-se a atuação do MST, que através da ocupação de terras não produtivas, tendo por base o previsto no Estatuto da Terra (1964) e na Constituição Federal (1988), de que a terra deve cumprir sua função social, pressiona para a implementação de uma política de reforma agrária pelo governo. (STÉDILE; FERNANDES, 1999). Em seus 30 anos de resistência popular, de espacialização da luta camponesa e de ocupação do território do latifúndio e do agronegócio, o MST tem emergido como uma das mais importantes forças sociais e políticas da América Latina e do mundo. Constitui-se como um movimento de massa, em âmbito nacional, de caráter popular, a partir do protagonismo dos próprios trabalhadores Sem Terra. Tendo como principal instrumento de pressão a ocupação de terra, se organiza como um movimento autônomo, independente da igreja, dos partidos e sindicatos, a partir do envolvimento da família. (STÉDILE; FERNANDES, 1999). Este fator de inclusão da família camponesa pelo MST insere a mulher na esfera pública, na luta política. A este respeito I. M. ${ }^{5}$, dirigente nacional do MST, declara:

Quando o movimento decide que a forma de adesão era familiar, a gente não tinha noção na época do significado disto para uma luta camponesa, numa sociedade extremamente patriarcal, conservadora, histórica de opressão da mulher. Eu acho que isto foi o grande acerto político, que possibilita que hoje no movimento tenha uma grande participação das mulheres.

Diferentemente dos espaços políticos, como o sindicato, o partido político, que "[...] separam a militância da relação e condição conjugal e familiar, o MST envolve toda a família nas suas lutas e manifestações políticas ao colocar no seu discurso a libertação econômica, social e política para a família trabalhadora rural". (ESMERALDO, 2013, p. 249). Esta característica, embora contraditória, tem sido crucial enquanto força política, pedagógica e de resistência, contribuindo para a formação de lideranças, incluindo as mulheres, os jovens e as crianças, que historicamente têm sido marginalizados e/ou excluídos do processo da luta

4 O MST foi formalizado em 1984, na cidade de Cascavel-PR.

5 Entrevista, 2011. As citações das entrevistas serão identificadas somente pelas iniciais dos entrevistados. 
social e das decisões políticas, até porque, tradicionalmente, as organizações sindicais têm sido representadas por apenas um membro da família, geralmente o "chefe da casa." Embora ingressem na luta como mães, esposas ou filhas, ocupando papéis secundários, dentro de um movimento social camponês que também reflete em sua organização a lógica da cultura patriarcal, as mulheres Sem Terra vão ocupando espaços e se tornam protagonistas na luta pela terra.

Um elemento que tem contribuído para a formação da consciência política e, posteriormente, a de gênero, é o fato de que muitas mulheres, que participam da constituição do MST, eram partícipes do movimento de resistência que a sociedade brasileira vivia nos anos 1980, na luta pela democracia, por direitos constitucionais e pela reforma agrária. "A maioria das lideranças que inicia o MST vem deste caldo: do partido, das oposições sindicais, da Pastoral da Terra. Muitas mulheres que entraram para o movimento já vinham das Comunidades de Base com grau de consciência política." " Uma evidência deste processo foi a luta política das mulheres para garantirem sua participação como delegadas no $1^{\circ}$ Congresso Nacional do MST, realizado em janeiro de 1985 em Curitiba, Paraná. I. G. (dirigente dos setores de educação e gênero do MST) ${ }^{7}$, relata: “[...] nós fizemos uma luta interna para ter $30 \%$ de mulheres no Congresso. E viemos. Aí as mulheres já vêm disputando espaço. Nós colocamos, foi aceito, tranquilo, não tivemos conflito, mas foi uma exigência das mulheres."

Tendo iniciado sua militância nas CEBs, na CPT e nas oposições sindicais, as mulheres camponesas não só participaram de forma afirmativa no Congresso, mas também organizaram a $1^{\text {a }}$ Assembleia de Mulheres Sem Terra e elaboraram um documento com reivindicações específicas, que compôs o documento final do Congresso. Esmeraldo (2013, p. 248) argumenta que embora as ações políticas organizadas pelas mulheres no Congresso se constituam numa primeira "[...] expressão material e simbólica de participação da mulher (para o interior do Movimento), essa representação vai potencializar ações políticas de mulheres Sem Terra, principalmente fora do MST, com mulheres sindicalistas, em parceria com movimentos autônomos de mulheres."

Além da organização interna, muitas mulheres Sem Terra também participavam do Movimento de Mulheres Trabalhadores Rurais, o qual emerge em meados dos anos 1980, no contexto da luta nacional pela democracia e da consolidação do movimento feminista e de mulheres no Brasil. (ALVAREZ, 1990). Ao caracterizar a participação das mulheres nos movimentos sociais dos anos 1980, Elisabeth Souza-Lobo (2011, p. 273) destaca os limites no nível da representação institucional, que permanece periférica para as mulheres, apesar

6 I. M., dirigente nacional do MST, Entrevista, 2011.

7 Entrevista, 2011. 
dos avanços de uma cidadania emergente. Maria José Carneiro (1994) aponta duas razões para a participação política da mulher camponesa: 1) o movimento de resistência dos trabalhadores rurais diante da intensificação da expropriação da terra e da exploração do trabalho; 2) a emergência de um movimento feminista e de mulheres que contribuiu para a formação de uma consciência na luta contra as desigualdades de gênero. $\mathrm{O}$ contexto das transformações da agricultura, como resultado da implementação de um modelo radical de capitalismo transnacional durante o período militar, produziu impactos sobre o trabalho da mulher camponesa, que foi substituído pela mecanização e pelo uso de insumos e fertilizantes. Christiane Campos (2011, p. 130) afirma que há um recorte de gênero no processo de enxugamento do mercado de trabalho no espaço rural. Com base em diversos estudos, a autora demostra que a expansão do agronegócio nas diversas regiões do país é acompanhada da exclusão e/ou inclusão precarizada da força de trabalho feminina, o que também contribui para a produção e reprodução da pobreza no campo. Este processo deu materialidade para a organização das mulheres camponesas, como revela I. G, dirigente dos setores de educação e gênero do $\mathrm{MST}^{8}$ : "A organização das mulheres nasce deste embate de expulsão das mulheres das tarefas da agricultura. E elas neste momento lutam pelo direito de serem agricultoras. Porque não existia a profissão de agricultora."

As principais demandas de gênero que potencializaram a organização do Movimento de Mulheres Trabalhadoras Rurais na década de 1980 têm sido o reconhecimento de seu status social como trabalhadora rural, sua incorporação nos sindicatos, o acesso aos benefícios de seguridade social, como a aposentadoria e o salário-maternidade ${ }^{9}$, e sua participação política. (SCHWENDLER, 2009). Além de não serem reconhecidas como trabalhadoras rurais, ao participarem da luta de classe contra o modelo de agricultura capitalista, onde se defendia também um novo sindicalismo, as mulheres começaram a perceber que elas eram marginalizadas nas principais instâncias de organização dos trabalhadores. (SHEPHEN, 1997; DEERE; LEÓN, 1999). A este respeito, S. K. ${ }^{10}$, dirigente nacional do MMC (Movimento de Mulheres Camponesas), destaca que a questão de gênero começa a aparecer dentro da luta de classe "[...] quando as mulheres vão tomando consciência de que elas estavam na luta sindical, mas não podiam votar e ser votadas." Esta exclusão retrata uma visão histórica presente na legislação (através do Código Civil de 1916) e reproduzida através da cultura e da educação de que a mulher deveria ser representada pelo "chefe

8 Entrevista, 2011.

9 Deere e León (1991) mostram que o Brasil foi pioneiro na América Latina na extensão dos benefícios sociais para mulheres trabalhadoras rurais; direito constitucional (1988) conquistado pelo movimento de mulheres.

10 Entrevista, 2011. 
de família”, e que seu trabalho na agricultura é apenas uma ajuda. Além de confinar as mulheres ao espaço privado, esta desvalorização e invisibilização do trabalho feminino estão pautadas numa concepção que não considera como trabalho o que está fora do âmbito das relações mercantis.

\section{A luta de gênero dentro da luta pela terra}

A organização das mulheres e sua participação na luta de classe foram cruciais para a percepção de que as questões de gênero precisavam compor a agenda política da luta social, para se desafiar as restrições que lhes eram impostas pelos regimes patriarcais de gênero. Nos acampamentos e assentamentos, as mulheres Sem Terra começam a se organizar e debater sua participação política, pois elas percebiam que para os homens havia mais oportunidade para participar dos espaços formativos e de decisão política, o que também contribuía para o desenvolvimento da liderança. Quando elas se organizaram internamente no MST, através do Coletivo de Gênero, ainda existia no movimento social uma forte compreensão de que as questões de gênero e de participação das mulheres seriam resolvidas através da luta de classe e da implementação do socialismo e, portanto, a luta pela transformação social, entendida como geral, devia ter prioridade sobre as lutas consideradas específicas, como as das mulheres ${ }^{11}$. Neste sentido, concorda-se com Miriam Nobre e Nalu Faria (1997) quando afirmam que:

As relações de gênero estruturam o conjunto das relações sociais e, portanto, não existe uma oposição entre questão de gênero (que seria específico) e questão da sociedade (que seria geral). Os mundos do trabalho, da política e da cultura também se organizam conforme a inserção de mulheres e homens, a partir de seus papéis masculinos e femininos. Portanto, não existe uma luta geral e depois uma específica, mas em todas as situações que queremos modificar, temos que considerar a superação das desigualdades de homens e mulheres. (NOBRE; FARIA, 1997, p. 31).

Lynn Stephen (1997, p. 223) argumenta que embora as mulheres camponesas tenham entrado na luta política na condição de mulheres da classe

11 Sobre gênero e classe, ver Paulilo (2006). 
trabalhadora; é no processo que elas se conscientizaram da necessidade de questionar sua posição subordinada de gênero dentro da igreja, dos sindicatos, e dos movimentos sociais em que participavam. Desse modo, pode-se afirmar que da defesa da participação da mulher na esfera pública, as mulheres Sem Terra avançam lentamente para a compreensão da necessidade da luta de gênero dentro da luta pela terra.

Para elas, o acampamento tem se constituído como um espaço por excelência para o desenvolvimento da liderança política, para consciência de gênero e de classe. "Depois de ir para o acampamento a gente tinha outra visão. $\mathrm{E}$ as mulheres através da própria luta conseguiram enxergar. Elas começam a participar quietinhas no acampamento e depois surge uma baita liderança." ${ }^{12}$ Como o acampamento - estágio de confronto da luta social - constitui-se numa experiência provisória, de vulnerabilidade, com possibilidade de conflito e despejo, o MST tem desenvolvido uma forte estrutura de resistência, baseada no princípio da participação democrática, com envolvimento de todos os membros da família. Tristan McCowan (2003, p. 2) ressalta que uma das dimensões em que o trabalho do MST assume um significado especial é o da participação. Como a maioria dos integrantes do movimento vem de uma condição de extrema exclusão, a tarefa do MST tem sido a de "[...] proporcionar-lhes a participação em diferentes esferas da sociedade - política, econômica e cultural - e o exercício de seus direitos como cidadãos". (MCCOWAN, 2003, p. 2).

Através dos núcleos de base e dos comitês/setores (de educação, saúde, produção, disciplina, alimentação, infraestrutura, comunicação, gênero, juventude, entre outros) os Sem Terra são informados, tomam decisões e assumem responsabilidades na estrutura coletiva. Além disso, participam de marchas, demonstrações, ocupações de espaços públicos para pressionar e negociar com órgãos governamentais e de espaços de formação. É o princípio da organização coletiva que conduz a luta social, de modo que não há uma clara divisão entre a esfera doméstica e o espaço público, tanto na organização do espaço físico (os barracos), bem como na divisão de tarefas e na estrutura organizativa do Movimento.

No conjunto da luta, onde as mulheres mais avançam por uma condição necessária, que é a da vivência coletiva, pois os nossos barracos são muito perto. Então não é possível nem desde a violência com a mulher, até a não participação do outro, porque ela é contada como um membro desta comunidade. Então ela precisa ir para o núcleo, ela precisa opinar.

12 I. V., líder no Assentamento da Annoni-RS, Entrevista, 2011. 
Então estes são os espaços em que as mulheres avançam. E na condição da luta pela terra as mulheres se colocam como dirigentes. (L.R, dirigente do MST-RS) ${ }^{13}$.

Estes dados de pesquisa confirmam as hipóteses levantadas por Maria Franco García (2004, p. 177), de que a organização espacial do acampamento e a sociabilidade comunitária permitem a quebra dos limites entre os espaços tradicionais do feminino e do masculino, redefinindo-os como espaço daqueles que lutam e resistem. Estudos como de Gonçalves (2005), Melo (2001), Schwendler (2003, 2013), Stephen (1997), revelam que, quando a mulher participa da organização e de um prolongado processo de ocupação e luta pela terra, ela começa a desnaturalizar sua condição histórica de subordinação e desempoderamento. Contudo, ao mesmo tempo em que a luta social traz a mulher para a arena sociopolítica, permanecem muitos aspectos das tradicionais relações e hierarquias de gênero. Embora se reproduzam na organização do acampamento, os regimes patriarcais de gênero se manifestam mais fortemente na dinâmica do assentamento de reforma agrária, onde a comunidade e as famílias assentadas se organizam para viabilizar a vida no campo, com forte ênfase na produção econômica. $\mathrm{O}$ fato do trabalho produtivo ainda ser concebido como território masculino tem impactado negativamente na condição de participação das mulheres nas decisões sobre a organização da unidade produtiva e na sua autonomia econômica. Além disto, a divisão sexual do trabalho, a naturalização da responsabilidade da mulher pelo chamado trabalho reprodutivo ${ }^{14}$, a forma de organização da produção e o isolamento espacial das famílias assentadas têm contribuído para um relativo retrocesso na fase do assentamento em termos da participação política da mulher camponesa. Seu protagonismo e empoderamento é mais visível na luta pelo acesso à terra. (SCHWENDLER, 2013).

Embora a emancipação sociopolítica e de gênero da mulher camponesa possa ser compreendida como produto da sua participação na luta pela terra, este processo não é linear e uniforme, nem automático. (SCHWENDLER, 2013). Leonilde Medeiros (2010, p. 11-12) aponta que a percepção da condição da subordinação não é um resultado imediato da participação, mas sim do modo como as pessoas participam e das possibilidades geradas para que a dominação de gênero seja desnaturalizada e as relações sociais reordenadas. A autora também

13 Entrevista, 2011.

14 O que se chama de trabalho reprodutivo - as tarefas domésticas, o cuidado das crianças e idosos, a produção e transformação dos alimentos, a criação dos animais para consumo, entre outros -, considerado de menor valor social, ou até como não trabalho, invisibiliza o papel da mulher na economia camponesa. 
ressalta que esta reorganização dos papéis de gênero é mais visível e contínua com mulheres que assumem posições de liderança e têm acesso a experiências práticas e análises teóricas.

A participação da mulher na luta social também tem levado à politização de seu papel de mãe e mulher, o que está fortemente vinculado com as condições materiais da produção da vida e a consciência de classe; um padrão comum na América Latina, particularmente, durante a luta pela democracia. Situação recorrente na luta pela terra é o fato de mulheres, com pouco estudo e sem "capital político anterior" (VIEIRA, 2010), tornarem-se grandes lideranças, conforme relato de C. L. (líder da Frente de Massas no Paraná) ${ }^{15}$ : "Se olhar companheiras quando chegaram e hoje. Hoje elas não têm medo de ir pra qualquer lugar, debater, discutir, levar os encaminhamentos, e isto graças à organização, ao estudo."

As mulheres têm participado dos diversos setores na organização interna do MST. Entretanto, elas têm se envolvido mais fortemente e assumido a coordenação dos setores de educação e da saúde, demostrando um forte sentimento de pertença. Estes espaços têm sido historicamente concebidos como um lugar natural da mulher; uma extensão do trabalho doméstico e do cuidado (LOURO, 1997), o que expressa a natureza do trabalho pedagógico feminino. Desde as primeiras ocupações de terra, o MST inaugura a luta pela educação formal nos acampamentos, através da Escola Itinerante ${ }^{16}$, e nos assentamentos, buscando desenvolver uma pedagogia libertadora, que tome por referência a história, a luta social e os saberes dos Sem Terra, em diálogo com conhecimentos socialmente produzidos e sistematizados na história da humanidade, e que reconheça os conhecimentos produzidos no campo como saberes legítimos de serem ensinados-aprendidos no currículo escolar. (SCHWENDLER, 2010). Este processo tem sido paradoxal em termos da emancipação da mulher. Ao mesmo tempo em que elas ocupam os setores tradicionalmente femininos, é através deles que muitas mulheres têm obtido o acesso à educação superior e desenvolvido sua liderança no movimento socia $1^{17}$. A este respeito, C. V. (coordenadora nacional do setor de educação do MST $)^{18}$ declara: "A educação foi um setor que

15 Entrevista, 2011.

16 É uma escola que acompanha o itinerário do acampamento, regulamentada pelo Conselho Estadual de Educação. Para maiores detalhes sobre a constituição da Escola Itinerante, ver Camini (2009).

$17 \mathrm{O}$ acesso ao Ensino Superior, inicialmente através do Curso de Pedagogia da Terra, tem sido uma conquista dos movimentos sociais, em particular do MST, e se realiza através de parceria com as universidades públicas, a partir do Programa Nacional de Educação na Reforma Agrária - PRONERA, vinculado ao Ministério do Desenvolvimento Agrário (1998) e, posteriormente, através das Licenciaturas em Educação do Campo, vinculadas ao Ministério da Educação (2008).

18 Entrevista, 2011. 
projetou militantes para todas as áreas. Como a maioria são mulheres, tivemos muitos quadros políticos. Se olharmos hoje, a maioria das mulheres que estão na direção nacional, grande parte veio do setor de educação."

No início da luta pela terra desenvolvida pelo MST, apesar da participação ativa da mulher, sua inclusão nos espaços decisórios da luta política (como a coordenação do acampamento e assentamento, a coordenação regional e nacional) era fortemente limitada pelas hierarquias de gênero e pela ausência de experiências político-organizativas. Na organização interna, “[...] as mulheres eram as que mais participavam no acampamento. A única diferença é que na direção se colocava mais os homens. Eles mesmos diziam, que quando é o poder tem que ser o homem, não a mulher, hoje tá diferente"19. Contudo, foi através da luta das mulheres e de sua participação nas instâncias de poder, mesmo que limitada, que foi possível provocar mudanças nas ideologias e habitus (BOURDIEU, 1990) de gênero. Um exemplo deste processo é a luta das mulheres no acampamento da Fazenda Annoni-RS - a primeira maior ocupação do MST (1985) -, onde se pautou pela primeira vez na reforma agrária o direito da mulher à terra, desafiando-se a concepção tradicional da terra para o homem, chefe de família. Esta foi a primeira situação em que a questão de gênero se torna explícita dentro da luta pela terra, mesmo que informalmente, e que mais tarde se formaliza através da cláusula da paridade de gênero (2000) e da obrigatoriedade da inclusão da mulher como beneficiária da reforma agrária $(2003)^{20}$.

Foi o MST, a luta das mulheres internas, que acabou criando uma consciência. Mas eu acho que não dá para deixar de registrar na história do movimento como uma conquista histórica esta questão de cadastrar as mulheres. Depois, era tranquilo nos acampamentos, as mulheres jovens, solteiras, que tiveram o direito de se cadastrar igual a um homem, que foi uma batalha feita em 1985 na ocupação da Annoni. Agora tem muita mulher que vai pra os acampamentos, solteira ou as casadas. Elas vão primeiro. (D. M., líder no Assentamento da Annoni-RS).

19 I.V. (liderança local, Assentamento da Annoni-RS, Entrevista, 2011).

20 Foi na Constituição Federal de 1988 que as mulheres conquistam o direito à terra, seja de modo individual, ou em nome do casal. Entretanto, como esta lei não era obrigatória e não foi assumida politicamente nas próprias organizações camponesas, nos órgãos de governo como o Instituto Nacional de Colonização e Reforma Agrária (INCRA), e também não era prioridade na luta das mulheres (DEERE, 2003), foi somente em 2000 que o direito da mulher à terra compôs a agenda política do movimento das mulheres e, em 2003 a agenda do governo. Com isto, a criação da Lei Ordinária n n $^{9}$ 91/2003 tornou compulsória a inclusão da mulher no acesso à terra de reforma agrária. 
É significativo, que há um discurso no mesmo campo semântico que sugere a inauguração da luta de gênero dentro da luta pela terra. As mulheres conquistaram alguns direitos porque participaram de um contexto mais amplo de luta e politizaram seus interesses de gênero através da participação e da organização de seus próprios espaços. Lá elas tornaram-se conscientes de que a reforma agrária não é neutra em termos de gênero; e como as mulheres têm sido historicamente excluídas dos principais espaços de decisão, elas perceberam a necessidade do seu empoderamento, através da criação de espaços específicos para a formação e a organização de mulheres.

\section{A transformação das relações de gênero como intencionalidade educativa}

Para modificar as relações de gênero e as estruturas de subordinação, as mulheres Sem Terra identificaram e politizaram as demandas de gênero e as transformaram em interesses estratégicos. Segundo Maxine Molyneux (1985, p. 232-33), enquanto os interesses práticos de gênero refletem a percepção das condições concretas da posição da mulher dentro da divisão sexual do trabalho, os interesses estratégicos de gênero resultam da análise da subordinação da mulher e da formulação de alternativas mais viáveis do que as existentes. O I Encontro Nacional de Mulheres Sem Terra realizado em $1996^{21}$, e a criação do Coletivo Nacional de Gênero (1996) dentro da estrutura organizativa do MST, incluindo homens e mulheres, são evidências e marcos deste processo ${ }^{22}$.

De forma estratégica, com a intencionalidade de promover transformações na cultura patriarcal, o Coletivo de Gênero do MST criou espaços formativos (teórico-práticos) para trabalhar com mulheres e homens. "A gente compreendia que não adiantava uma dúzia de mulheres ter clareza e ser a vanguarda e o resto da base não ter a compreensão. A gente fazia formação massiva." ${ }^{23}$ Também havia o entendimento de que: "[...] não basta nós conscientizar as mulheres, mas é preciso que os homens também tomem consciência da opressão de gênero que é exercida por eles culturalmente"24. A partir do protagonismo das mulheres,

21 Este Encontro deliberou pela elaboração de um plano de ação tendo como foco a ampliação da participação das mulheres nas instâncias de poder e a construção de novas relações de gênero no interior do movimento.

22 Posteriormente, o Coletivo de Gênero foi transformado em Setor.

23 I. M., Assentamento da Annoni-RS, Entrevista, 2011.

24 I.G., dirigente nos setores de educação e gênero do MST, Entrevista, 2011. 
a temática de gênero foi assumida como uma política de ação do MST, sendo trabalhada em todos os seus cursos de formação (nos acampamentos, assentamentos e nas instâncias de coordenação) ${ }^{25}$. Ao mesmo tempo, mantinha-se a necessidade da organização e criação de processos pedagógicos específicos para preparar a mulher para uma atuação mais qualificada no movimento social de luta pela terra. "As mulheres precisam de um espaço próprio, senão não fala, não tem esta cumplicidade. A opressão é muito grande.”26

Atualmente, no estado do Paraná, o Setor de Gênero do MST vem desenvolvendo, em parceira com a Secretaria de Políticas para as Mulheres, um processo formativo com as mulheres assentadas e acampadas, em especial com aquelas que assumem funções de liderança em suas comunidades. Tendo participado destes espaços formativos ${ }^{27}$, inclusive como assessora, foi possível perceber a importância da formação em gênero com a intencionalidade pedagógica de contribuir no processo de empoderamento das mulheres camponesas. Deere e León (2001) argumentam que como a subordinação da mulher dentro da ideologia patriarcal parece ser natural, seu empoderamento precisa ser induzido através de um processo de conscientização da discriminação de gênero; implica em modificar a baixa autoestima e a crença das mulheres em relação às suas capacidades e direitos. Compreendido como condição para desafiar relações e estruturas opressivas e fomentar a transformação social, o empoderamento como processo envolve reconhecimento, construção de capacidades e ação individual e coletiva. (MURPHY-GRAHAM, 2012, p. 18).

Evidencia-se que o contato da mulher camponesa com o discurso feminista, o envolvimento nas lutas sociais e sua organização em nível local, nacional e internacional têm promovido a politização e a organização em torno dos interesses estratégicos de gênero. (SCHWENDLER, 2013). Na década de 1990, a organização das mulheres de movimentos sociais mistos e autônomos, através da Articulação Nacional das Mulheres Trabalhadoras Rurais (ANMTR) ${ }^{28}$, e sua

25 No processo de formação pedagógica, destacam-se vários materiais elaborados pelo Coletivo Nacional de Gênero do MST, entre eles, as cartilhas A Questão da Mulher no MST(1996); A questão de Gênero no MST (1997), e o caderno de formação Compreender e construir novas relações de gênero (1998).

26 I. M., dirigente nacional do MST, Entrevista, 2011.

27 De 10 a 13 de novembro de 2014, realizou-se em Cascavel-PR, o Encontro Estadual de Mulheres da Reforma Agrária do Paraná, que reuniu mais de 200 mulheres para problematizar as questões de gênero em sua articulação com a luta de classe, com a reforma agrária popular e a agroecologia, incluindo a discussão sobre o papel das mulheres na produção da renda e do alimento saudável para a autossustentação das famílias, assim como o combate da violência contra as mulheres.

28 Na década de 1980 as mulheres que participavam dos sindicatos, da CPT, das CEBs e do MST se organizavam também nos Movimentos de Mulheres Trabalhadoras Rurais (MMTRs). Com o objetivo de unificar a luta de gênero com a luta de classes, em 1995, durante o I Encontro Nacional 
inserção de forma organizada na Coordenação Latino-Americana de Organizações do Campo (CLOC) e na Via Campesina - considerada politicamente o mais importante movimento agrário transnacional do mundo (DESMARAIS, 2009) -, têm contribuído para a construção de uma agenda de gênero dentro da luta de classe. Nestes espaços de luta política, as mulheres acumulam força política e conhecimento para compreenderem a questão agrária no contexto nacional e internacional e o papel da agricultura camponesa na produção da soberania alimentar. Ao mesmo tempo, a partir da categoria teórica de gênero, articulada à categoria de classe, elas problematizam a produção e reprodução da subalternização da mulher na sociedade e, particularmente, na cultura camponesa; portanto, constroem propostas contra-hegemônicas que desafiam os regimes patriarcais de gênero que se reproduzem também nos movimentos sociais em que participam.

Deere e Royce (2009, p. 17) ressaltam que a incorporação das questões de gênero nos movimentos transnacionais é parcialmente um resultado do desenvolvimento de movimentos nacionais de mulheres rurais nos anos 1990 que não tiveram receio de se identificar com o feminismo. Contribuíram ainda para este processo, segundo os autores, o contato dos movimentos sociais da América Latina com outros países onde o discurso da igualdade de gênero é mais avançado, e a compreensão de que a transformação das relações de gênero é uma pré-condição para a implementação dos princípios da igualdade, justiça social e cidadania. Esmeraldo (2013) também destaca o papel da CLOC e Via Campesina para que o conceito de gênero como categoria teórica fosse aceito pelas forças masculinas, passando a contribuir tanto na análise e compreensão da condição de desigualdade vivenciada historicamente pela mulher camponesa, quanto na orientação das lutas específicas e sua relação com a luta de classe.

A participação das mulheres na CLOC/Via Campesina de forma organizada, através da Assembleia de Mulheres, foi crucial para que a paridade de gênero fosse assumida nos movimentos sociais mistos em nível local e transnacional ${ }^{29}$. Um claro exemplo deste processo é a incorporação da cláusula da

de Mulheres Trabalhadoras Rurais, foi criada a Articulação Nacional de Mulheres Trabalhadoras Rurais (ANMTR). Na maioria dos estados, com exceção do Norte e Nordeste, os movimentos autônomos se organizam, desde 2004, através do Movimento das Mulheres Camponesas (MMC).

29 As mulheres participam como protagonistas nos espaços internacionais, desde a $1^{\text {a }}$ Conferência de criação da Via Campesina que ocorreu na Bélgica em 1993 e na I Conferência da Coordenação Latino-Americana das Organizações Camponesas - CLOC, em 1994, no Peru. Para promover o debate e fomentar ações políticas de gênero, durante a $2^{\mathrm{a}}$ Conferência da Via Campesina (1996), no México, elas criaram um grupo permanente de trabalho, a Comissão de Mulheres. Um dos reflexos desta ação é a realização da $1^{\mathrm{a}}$ Assembleia Latino-Americana de Mulheres, realizada antes da II Conferência da CLOC, em Brasília (1997), que aprovou a paridade de gênero na participação. Segundo Desmarais (2011), em 2000, na III Conferência da Via Campesina, na Índia, 43\% dos 
paridade de gênero, dentro das normas organizativas do MST, desde 2000, a partir do protagonismo das mulheres ${ }^{30}$. Dados de pesquisa (SCHWENDLER, 2013) revelam o grau de impacto destas políticas de gênero no processo de emancipação e empoderamento das mulheres. "Isto deu um salto de qualidade na participação das mulheres, da base até as direções, que não tinha visto e não vejo em nenhuma organização no Brasil. ${ }^{{ }^{31}}$ D. J. recorda que quando ingressou no MST em 1989, a participação da mulher nas esferas de discussão e decisão ainda era pequena. "Hoje temos muitas mulheres comandando o movimento de igual para igual, na direção estadual, nacional, nos diversos setores. [Por exemplo], no setor de frente de massa, que prepara pra mobilização, e que tradicionalmente era de homens." Com esta mudança na organização interna, as mulheres participam não somente das atividades organizativas, mas também nos encontros de formação, o que contribui para a ampliação do conhecimento, essencial para o enfrentamento da cultura do silêncio e da subalternização. "Ter a mulher coordenando a frente de massa é fundamental, porque se vão só os homens, falam, falam, e daí eles vão tirar as dúvidas, e as mulheres ficam num cantinho e vão embora. As mulheres ficam geralmente muito inseguras pra perguntar pra um homem." ${ }^{32}$

A paridade de gênero dentro da luta pela terra tem ampliado as possibilidades de desenvolvimento do capital político e cultural das mulheres. (BOURDIEU, 1986). Daniel Schugurensky (2000, p. 6) analisa o “[...] capital político como uma capacidade de influenciar nas decisões políticas" no espaço público e privado. Os saberes aprendidos na vivência da luta pela terra, nas audiências e negociações com órgãos públicos, nas marchas e mobilizações, no trabalho de equipe e de coordenação, assim como nos espaços de formação teórica, têm potencializado a atuação política e o protagonismo das mulheres. Uma evidência deste processo tem sido a ação organizada das mulheres do MST, do MMC, dentre outros movimentos sociais que integram a Via Campesina (Brasil), no Dia Internacional da Mulher, como parte da jornada de luta contra a intensificação do modelo hegemônico de desenvolvimento do campo, baseado no agronegócio ${ }^{33}$.

delegados eram mulheres. Elas também organizaram a I Assembleia Internacional de Mulheres, o que contribui para a aprovação de um documento sobre gênero e a institucionalização da paridade de gênero na comissão coordenadora da Via Campesina.

30 Em seu IV Congresso (agosto de 2000), o MST estabeleceu que os núcleos de base tivessem um homem e uma mulher na coordenação. Progressivamente, esta medida tem sido adotada nos diferentes níveis e instâncias da estrutura organizativa.

31 J. D., líder regional no Paraná, Entrevista, 2011.

32 C. L., líder da Frente de Massas no Paraná, Entrevista, 2011.

33 Esta estratégia de luta política e de gênero foi assumida em março de 2000, durante o I Acampamento Nacional de Mulheres Trabalhadoras Rurais do Brasil, organizado pela ANMTR, e que reuniu cerca de 3.000 mulheres em Brasília. 
Esta atuação tem sido intensificada desde o marcante episódio em 2006, onde as mulheres camponesas ocuparam o Viveiro da Aracruz Celulose no Rio Grande do Sul e destruíram as mudas transgênicas destinadas para a monocultura de eucalipto, como forma de denunciar o impacto deste modelo de desenvolvimento no modo de vida e na economia camponesa. (SCHWENDLER, 2014; CARLOS; CONTE, 2009).

Esta forma de protesto revela que as mulheres se superaram não somente no que lhes é esperado enquanto papéis de gênero, mas também pela sua capacidade organizativa e propositiva. São mulheres do campo, muitas delas sem muito estudo, mas com uma grande capacidade organizativa e um "saber de experiência feito" (FREIRE, 1997), fruto de sua participação na luta social. Isto também mostra que os movimentos de mulheres não têm restringido suas lutas "[...] às reivindicações históricas de inclusão das mulheres em políticas públicas, mas avançam na proposição de um modelo de desenvolvimento para o campo que combina questões estratégicas presentes nos movimentos ecologistas/ambientalistas com elementos trazidos historicamente pelo feminismo". (SILIPRANDI, 2013, p. 336). Aqui aparece claramente a dimensão da experiência nas palavras de Edward Thompson (1981), que possibilita às mulheres um acúmulo de conhecimento, um saber social gerado na luta pela igualdade de gênero, pela justiça social, contra todas as formas de discriminação e contra o processo de exploração do trabalho e de despossessão dos(as) camponeses(as) de seu território. Destaca-se aqui a importância de compreender as trabalhadoras do campo como sujeitos históricos que

[...] experimentam suas situações e relações produtivas determinadas como necessidades e interesses e como antagonismos, e em seguida "tratam" essa experiência em sua consciência e sua cultura [...] e em seguida (muitas vezes, mas nem sempre, através das estruturas de classes resultantes) agem, por sua vez, sobre sua situação determinada. (THOMPSON, 1981, p. 182).

Sua experiência de trabalho, especificamente na produção e transformação de alimentos, também tem produzido um saber e uma consciência social do cuidado com o Planeta, com a produção da vida, com a preservação das sementes, concebidas como patrimônio da humanidade. Essa experiência, como "atoras" econômicas, tem tido um papel preponderante "[...] na resistência à agricultura de mercado e sua tentativa de homogeneizar a produção do campo" (FARIA, 2009 , p. 24), assim como na proposição de políticas para o campo, pautadas 
num modelo de agricultura sustentável, agroecológico com vistas à soberania alimentar. A problematização da inserção da mulher na produção através da prática política tem gerado, nas palavras de Maria Nobre Damasceno (1995, p. 25), um saber social que é "[...] gestado no cotidiano da vida, do trabalho, e da luta diária, é a expressão concreta da experiência de um grupo social, um saber que é útil ao trabalho, aos enfrentamentos vividos cotidianamente por estes atores sociais." Este saber constitui-se como instrumento para enfrentar situações mais amplas, como a questão agrária, e a necessidade da construção de políticas afirmativas de gênero.

\section{Conclusão}

Dando ênfase à práxis dos movimentos sociais como formadora dos sujeitos, este artigo analisou o processo pedagógico da luta de gênero dentro da luta pela terra, protagonizada pelas mulheres Sem Terra. Pode-se inferir que a participação das mulheres desde o princípio da ocupação de terras organizada pelo MST, mesmo em papéis secundários, foi crucial para a sua formação político-organizativa a partir de uma compreensão de classe, para a ampliação de seu conhecimento, e para uma leitura crítica das desigualdades de gênero. Entretanto, o desenvolvimento da consciência de gênero foi gerado em função da sua inserção no movimento de mulheres, e de sua organização específica a partir de um referencial teórico feminista, que toma a categoria de gênero como instrumento de análise das estruturas e práticas que produzem as desigualdades de gênero, mas também como ferramenta para a proposição de políticas e ações estratégicas com vistas à transformação das relações e ideologias de gênero.

A compreensão da subalternização e a reelaboração da visão de mundo têm sido fundantes para que as mulheres protagonizassem, dentro da luta pela terra, a luta de gênero. Neste processo, ressalta-se a politização dos interesses práticos de gênero e sua transformação em interesses estratégicos, a partir da intencionalidade sociopolítico-educativa. A participação das mulheres camponesas nos movimentos sociais de luta de classe em nível local, nacional e transnacional, sua articulação interna e sua organização específica têm ampliado seu saber social, o que contribuiu para seu empoderamento, e consequentemente, sua ação estratégico-organizativa.

Cabe ressaltar que como este processo não é linear e nem atinge as mulheres da mesma forma, ao mesmo tempo em que ocorre um processo avançado de organização e politização, o grau de subalternização da mulher camponesa 
ainda é bastante visível, até porque o nível e as condições de participação e envolvimento são diferenciados e, ao mesmo tempo, o próprio movimento social vai se construindo com a incorporação contínua de sujeitos destituídos de diversos direitos, incluindo a questão de gênero. Pode-se inferir que na luta pela terra há um processo pedagógico de reconstrução dos papéis de gênero, com intencionalidade educativa. Este, porém, é carregado de limites, os quais refletem os regimes patriarcais de gênero, que são produzidos e reproduzidos nos distintos espaços e instituições (como a família, a escola, o movimento social, o partido, a igreja, o mercado, o Estado) e, apropriados pelo mercado de trabalho no processo de acumulação do capital, enquanto justificativa ideológica das condições diferenciadas por gênero.

Ao mesmo tempo em que se reconhece que a materialidade da luta social é pedagógica, principalmente quando são construídas intencionalmente estratégias e espaços onde os sujeitos possam vivenciar relações mais igualitárias de gênero, compreende-se que o processo de empoderamento das mulheres e a transformação das relações de gênero requerem também a organização de espaços formativos, onde as pessoas possam, a partir de uma pedagogia crítica e dialógica (FREIRE, 1992), reconhecer e problematizar a produção e reprodução das desigualdades de gênero em seu cotidiano e na história da sociedade. Conclui-se que o trabalho pedagógico com ênfase nas questões de gênero contribui para o enfrentamento das desigualdades e da subalternização, pois amplia a autoconfiança, o conhecimento e a capacidade das mulheres de se organizarem para viabilizar os interesses estratégicos de gênero. Contudo, embora este processo formativo, com intencionalidade pedagógica, seja crucial para a transformação da cultura patriarcal, a transformação das relações de gênero não se viabiliza se não estiver ancorada em leis e políticas afirmativas que garantam à mulher condições efetivas de participação política, econômica e social.

\section{REFERÊNCIAS}

ALVAREZ, Sonia. Engendering Democracy in Brazil: Women's Movements in Transition Politics. Princeton: Princeton University Press, 1990.

ARROYO, Miguel. Pedagogias em movimento. O que temos a aprender dos movimentos sociais. Currículo Sem Fronteiras, v. 3, n. 1, p. 28-49, jan./jun. 2003.

BOURDIEU, Pierre. The logic of practice. Cambridge: Polity Press, 1990. p. 52-65. 
BOURDIEU, Pierre. The Forms of Capital. In: RICHARDSON, J. (Ed.). Handbook of Theory and Research for the Sociology of Education. New York: Greenwood, 1986. p. 241-258. BOYDSTON, Jeanne. Gender as a Question of Historical Analysis. Gender \& History, v. 20, n., p. 3 558-583, Nov. 2008.

CALDART, Roseli S. Pedagogia do Movimento Sem terra: escola é mais do que escola. Petrópolis, RJ: Vozes, 2000.

CAMINI, Isabela. Escola itinerante na fronteira de uma nova escola. São Paulo: Expressão Popular, 2009.

CAMPOS, Christiane S. A face feminina da pobreza em meio à riqueza do agronegócio. Buenos Aires: CLACSO, 2011.

CARLOS, Daiane dos S.; CONTE, Isaura I. Oito de março de 2006: em defesa da vida, mais um marco na luta das mulheres camponesas. In: PALUDO, Conceição (Org.). Mulheres, Resistência e Luta: em defesa da vida. São Leopoldo: Cebi, 2009. p. 133-167.

CARNEIRO, Maria J. Mulheres no campo: notas sobre sua participação política e a condição social do gênero. Estudos Sociedade e Agricultura, n. 2, p. 11-22, jun. 1994.

DAMASCENO, Maria Nobre. A construção do saber social pelo camponês na sua prática produtiva e política. In: THERRIEN, Jacques; DAMASCENO, Maria Nobre (Coords.). Educação e escola do Campo. Campinas, SP: Papirus, 1993.

DAMASCENO, Maria Nobre. O saber social e a construção da identidade. Contexto \& Educação, Ijuí: UNIJUÍ, ano 9, n 38, abr./jun. 1995.

DEERE, Carmen Diana. Women's Land Rights and Rural Social Movements in the Brazilian Agrarian Reform. Journal of Agrarian Change, v. 3, n. 1\&2, p. 257-288, 2003.

DEERE, Carmen Diana; LEÓN, Magdalena. Towards a Gendered Analysis of the Brazilian Agrarian Reform. Occasional paper, Latin American Studies Consortium of New England. Storrs, CT: Center for Latin American \& Caribbean Studies, University of Connecticut, 1999.

DEERE, Carmen Diana. Empowering Women: Land and Property Rights in Latin America. Pitt Latin American Series. Pittsburgh, Pa.: University of Pittsburgh Press, 2001.

DEERE, Carmen Diana; ROYCE, Frederick S. Rural Social Movements in Latin America: Organizing for Sustainable Livelihoods. United States of America: University Press of Florida, 2009.

DESMARAIS, Annette A. La Vía Campesina: Globalising Peasants. In: DEERE, Carmen Diana; ROYCE, Frederick S. Rural Social Movements in Latin America: Organizing for Sustainable Livelihoods. United States of America: University Press of Florida, 2009. p. 33-53.

DESMARAIS, Annette A. The International Women's Commission of La Via Campesina. In: VISVANATHAN, Naline et al. (Eds.). The Women, Gender and Development Reader Second. New York: Fernwood Publishing Halifax Winnipeg; London: Zed Books, 2011. 
ESMERALDO, Gema G. O protagonismo político de mulheres rurais por seu reconhecimento econômico e social. In: NEVES, Delma P.; MEDEIROS, Leonilde S. de (Orgs.). Mulheres camponesas: trabalho produtivo e engajamentos políticos. Niterói: Alternativa, 2013. p. 237-256.

FARIA, Nalu. Economia feminista e agenda de luta das mulheres no meio rural. In: BUTTO, Andrea (Org.). Estatísticas rurais e a economia feminista: um olhar sobre o trabalho das mulheres. Brasília: NEAD, 2009.

FERNANDES, Bernardo M. Questão agrária: conflitualidade e desenvolvimento territorial. In: BUAINAIN, A. M. (Org.). Luta pela terra, reforma agrária e gestão de conflitos no Brasil. Campinas, SP: Unicamp, 2008. p. 173-230.

FRANCO GARCÍA, María. A luta pela terra sob enfoque de gênero: Os lugares da diferença no Pontal do Paranapanema. Tese (Doutorado) - Universidade Estadual Paulista Júlio de Mesquita Filho, UNESP, Faculdade de Ciência e Tecnologia, Presidente Prudente, 2004.

FREIRE, Paulo. Pedagogia do oprimido. Rio de Janeiro: Paz e Terra, 1992.

FREIRE, Paulo. Pedagogia da autonomia: saberes necessários à prática educativa. São Paulo: Paz e Terra, 1997.

GOHN, Maria da Glória. Educação não-formal e cultura política. São Paulo: Cortez, 1999.

GOHN, Maria da Glória. Educação não-formal, participação da sociedade civil e estruturas colegiadas nas escolas. Ensaio: avaliação e políticas públicas em educação, Rio de Janeiro, v. 14, n. 50, p. 27-38, jan./mar. 2006.

GONÇALVES, Renata, H. Vamos acampar: a luta pela terra e a busca pelo assentamento de novas relações de gênero no MST do Pontal do Paranapanema. Tese (Doutorado) Programa de Pós-Graduação em Ciências Sociais, UNICAMP, Campinas, SP, 2005.

GRAMSCI, Antonio. A concepção dialética da história. Trad. Carlos Nelson Coutinho. 3. ed. Rio de Janeiro: Civilização Brasileira, 1984.

JACOBS, Susie. Gender and Agrarian Reform. New York: London: Routledge, 2010.

LOURO, Guacira L. Gênero, sexualidade e educação. Petrópolis, RJ: Vozes, 1997.

MARRE, Jacques L. História de Vida e Método Biográfico. Cadernos de Sociologia, Porto Alegre, v. 3, n. 3, p. 89-141, jan./jul. 1991.

MCCOWAN, Tristan. Participation and Education in the Landless People's Movement of Brazil. Journal for Critical Educational Policy Studies, v. 1, n. 1, March 2003.

MELO, Denise. A construção da subjetividade de mulheres assentadas pelo MST. Dissertação (Mestrado) - Universidade Estadual de Campinas, Campinas, SP, 2001. 
MEDEIROS, Leonilde S. de. Assentamentos rurais e gênero: temas de reflexão e pesquisa. In: LOPES, Adriana; ZARZAR, Andrea Butto. (Orgs.). Mulheres na reforma agrária: a experiência recente no Brasil. Brasília: MDA, 2010. p. 7-18.

MOLYNEUX, Maxine. Mobilization without Emancipation? Women's Interests, the State, and Revolution in Nicaragua. Feminist Studies, v. 11, n. 2, p. 227-254, Summer 1985.

MURPHY-GRAHAM, Erin. Opening minds, improving lives: education and women's empowerment in Honduras. Nashville: Vanderbilt University Press, 2012.

NOBRE, Miriam; FARIA, Nalu. Gênero e desigualdade. Cadernos Sempreviva. São Paulo: SOF - Sempreviva Organização Feminsta, 1997.

PAULILO, Maria Ignez S. El género y la clase en los movimientos de mujeres agricultoras de Brasil. Agricultura, Sociedad y Desarrollo, v. 3, p. 175-196, 2006.

PINTO, Célia R. Movimentos sociais: Espaços privilegiados a mulher enquanto sujeito político. In: BRUSCHINI, C.; COSTA, A. (Ed.). Uma questão de gênero. Rio de Janeiro: Rosa dos Tempos, 1992.

PORTELLI, Alessandro. What Makes Oral History Different. In: PERKS, Robert; THOMSON, Alistair (Eds.). The Oral History Reader. 2. ed. London: New York: Routledge, 2006.

SCHUGURENSKY, Daniel. Citizenship Learning and Democratic Engagement: Political Capital Revisited. Paper presented at the 41st Annual Adult Education Research Conference, Vancouver: AERC, n. 2-4, p. 417-422, June 2000.

SCHWENDLER, Sonia F. The Construction of the Feminine in the Struggle for Land and in the Social Re-creation of the Settlement. In: VIEIRA, E. R. P. (Ed.). The Sights and Voices of Despossession: The Fight for the Land and the Emerging Culture of the MST (The Movement of the Landless Rural Workers of Brazil). University of Nottingham, 2003. Disponível em: <http://www.landless-voices.org>. Acesso em: 20 nov. 2013.

SCHWENDLER, Sonia F. A participação da mulher na luta pela terra: dilemas e conquistas. In: FERNANDES, B. M.; MEDEIROS, L. S. de; PAULILO, M. I. (Orgs.). Lutas camponesas contemporâneas: condições, dilemas e conquistas. São Paulo: UNESP; Brasília: NEAD, 2009. v. 2. p. 203-221.

SCHWENDLER, Sonia F. Educação e movimentos sociais: uma reflexão a partir da pedagogia do oprimido. In: MIRANDA, S. G., SCHWENDLER, S. F. (Eds). Educação do Campo em movimento: teoria e prática cotidiana. Curitiba: Ed. UFPR, 2010. v. 1.

SCHWENDLER, Sonia F. Women's Emancipation through Participation in Land Struggle. Tese (Doutorado) - University of London, London, 2013.

SCHWENDLER, Sonia F. International Women's Day in the Brazilian Countryside: New Forms of Political Protest and Resistance. In: History of Women in the Americas. 2014. v. 2. Disponível em: <http://journals.sas.ac.uk/hwa/article/view/2090>. Acesso em: 18 jun. 2014. 
SCOTT, Joan W. Gender: A Useful Category of Historical Analysis. The American Historical Review, v. 91, n. 5, p. 1053-1075, Dec. 1986.

SILIPRANDI, Emma. Mulheres agricultoras e a construção dos movimentos agroecológicos no Brasil. In: NEVES, Delma P.; MEDEIROS, Leonilde S. de (Orgs.). Mulheres camponesas: trabalho produtivo e engajamentos políticos. Niterói: Alternativa, 2013. p. 329-343.

SOUZA, Maria Antônia de. Educação do Campo: propostas e práticas pedagógicas do MST. Petrópolis, RJ: Vozes, 2006.

SOUZA-LOBO, Elisabeth. A classe operária tem dois sexos: trabalho, dominação e resistência. 2. ed. São Paulo: Editora Fundação Perseu Abramo, 2011.

STEDILE, João Pedro; FERNANDES, Bernardo M. Brava gente: a trajetória do MST e a luta pela terra no Brasil. São Paulo: Fundação Perseu Abramo, 1999.

STEPHEN, Lynn. Women and Social Movements in Latin America: Power from Below. Austin: University of Texas Press, 1997.

THOMPSON, Edward. A miséria da teoria ou um planetário de erros. Rio de Janeiro: Zahar, 1981.

THOMPSON, Paul. The Voice of the Past: Oral History. 2. ed. Oxford: Oxford University Press, 1988.

VIEIRA, Else. Women in Brazilian Politics (lecture). London: Queen Mary University of London, 2010.

WALBY, Sylvia. Gender Transformations. Routledge: London, 1997.

Texto recebido em 12 de fevereiro de 2015.

Texto aprovado em 02 de março de 2015. 
